\title{
Is It Better to Use Gate Opening as Control Variable than Discharge to Control Irrigation Canals?
}

\author{
Klaudia Horváth ${ }^{1}$; Eduard Galvis²; Manuel Gómez Valentín ${ }^{3}$; and José Rodellar Benedé ${ }^{4}$
}

\begin{abstract}
Centralized model predictive controllers are common in water systems. The control action variable can be the discharge, and the subsystems (canal pools) are modeled separately. This paper focuses on short canal pools where the interactions are stronger between canal pools. Could this procedure be better if gate openings were used as control action variables and the interconnected system were modeled for the controller? Model predictive controllers (MPCs) were developed using the discharge and the gate opening as control action variable and tested experimentally using the laboratory canal of the Technical University of Catalonia. It was found that for centralized MPCs for short canal pools, the use of gate opening as control action variable is more beneficial than discharge. Another additional advantage is that in this way it is possible to put constraints on the gate opening and the change of gate opening, which are important to the limitations of the physical system. DOI: 10.1061/(ASCE)IR.1943-4774.0000798. @ 2014 American Society of Civil Engineers.
\end{abstract}

Author keywords: Canal; Open channel; Irrigation; Active control; Feedback control; Gates; Automation; Resonance.

\section{Introduction}

Canal automation in irrigation canals is a way to reduce water losses and have more ecological and economic use of water. Irrigation canals can be controlled in a centralized (Rivas-Perez et al. 2002; Montazar et al. 2005; van Overloop et al. 2010a), decentralized (Li et al. 2004; Lemos et al. 2007; Gómez et al. 2002), or distributed manner (Maestre Torreblanca 2010). For decentralized control, each canal pool is controlled separately without sharing information about the state of the other pools. For centralized control, all measurements are sent to a central unit and a decision is made about the control movement taking into account the state of the whole canal system. A third alternative between centralized and decentralized approach is distributed control, when each controller of the subsystems communicates an order to find a cooperative solution for the overall control problem.

For all types of control architecture, different control action variables can be used: discharge or gate opening. When gate opening is used as control action variable, the controller calculates directly the gate opening and sends this information to the actuator (gate position controller). When the discharge is the control action variable, the controller calculates the discharge and the openings are set based on the desired discharge. The way of setting these gate

${ }^{1} \mathrm{Ph}$. D., Dept. of Environmental, Hydraulic and Maritime Engineering, Technical Univ. of Catalonia, Jordi Girona 1, 08031 Barcelona, Spain; presently, Post-Doctoral Researcher, École des Mines de Douai, Dept. of Informatics and Automation, 764 Blvd. Lahure, 59500 Douai, France (corresponding author). E-mail: klaudia.horvath@mines-douai.fr

${ }^{2}$ Ph.D. Student, Dept. of Applied Mathematics III, Technical Univ. of Catalonia, Jordi Girona 1, 08031 Barcelona, Spain.

${ }^{3}$ Full Professor, Dept. of Environmental, Hydraulic and Maritime Engineering, Technical Univ. of Catalonia, Jordi Girona 1, 08031 Barcelona, Spain.

${ }^{4}$ Full Professor, Dept. of Applied Mathematics III, Technical Univ. of Catalonia, Jordi Girona 1, 08031 Barcelona, Spain.

Note. This manuscript was submitted on December 16, 2013; approved on June 30, 2014; published online on August 12, 2014. Discussion period open until January 12, 2015; separate discussions must be submitted for individual papers. This paper is part of the Journal of Irrigation and Drainage Engineering, (C) ASCE, ISSN 0733-9437/04014054(12)/\$25.00. openings can be another automatic controller with a higher sampling rate [like a proportional-integral-derivative (PID) controller] or an equation converting the discharge into gate opening. This equation can be the inverted gate equation or a more complex equation incorporating the changes of water level during a sampling instant (Litrico et al. 2008).

For decentralized control, the goal is to reduce the coupling between the subsystems because it can cause performance degradation (Welz et al. 2005; Li and De Schutter 2010). One decoupling method is using the discharge as control action variable (Schuurmans 1997). The choice between discharge or gate opening as control action variable has been investigated in Malaterre and Baume (1999). Four different types of benchmark canals have been studied by using decentralized PI controllers. In all cases the scenario of using discharge as control action variable with another controller taking into account the anticipated water level changes gave the best results.

However, the choice of control action variables has not been analyzed yet for centralized and distributed systems. For both control configurations it raises interest in how the choice of the control action variables can effect the performance of the controller. This paper focuses on the centralized configuration. For model predictive control (MPC) of centralized systems, the goal is to have a model that is able to describe the whole system dynamics. In this case it might be preferable to use gate openings as control action variable. This question is investigated in this study for short canal pools. These canal pools are completely affected by backwater, therefore a disturbance from downstream can reach the upstream end of the canal. Therefore the interaction between canal pools is more prominent, hence a difference is expected between the different use of control action variables. The hypothesis is that for centralized MPC of short and resonance-sensitive canals, it is better to use gate openings as control action variable than discharge.

This hypothesis is investigated through numerical and experimental models. Model predictive controllers are developed and implemented in the laboratory canal of the Technical University of Catalonia. First, the gate modeling then the different models are discussed. Next the controller development is described, and finally the experimental results are shown and discussed. 
Table 1. Geometric Parameters of the UPC-PAC

\begin{tabular}{lc}
\hline Parameter & Value \\
\hline $\boldsymbol{n}$ & 0.016 \\
$\boldsymbol{B}$ & $0.44 \mathrm{~m}$ \\
$\boldsymbol{S}_{\boldsymbol{b}}$ & $0 \mathrm{~m} / \mathrm{m}$ \\
$\boldsymbol{X}$ & $220 \mathrm{~m}$ \\
Pool 1 & $87.0 \mathrm{~m}$ \\
Pool 2 & $90.2 \mathrm{~m}$ \\
Pool 3 & $43.5 \mathrm{~m}$ \\
\hline
\end{tabular}

\section{Description of the Laboratory Canal}

The Canal de Prueba de Algoritmos de Control-Universitat Politécnica de Catalunya (UPC-PAC canal) is located in Barcelona, Spain, at the Northern Campus of the Technical University of Catalonia. It was specially designed to develop basic and applied research in the field of control of irrigation canals. It has a serpentine shape in order to achieve the greatest length using a small surface area. The canal has zero slope. In this way it is possible to achieve considerable time delay, approximately $80 \mathrm{~s}$. The geometrical data are summarized in Table 1, where $n$ is the Manning's roughness coefficient, $B$ is the channel width $(\mathrm{m}), S_{b}$ is the bottom slope $(\mathrm{m} / \mathrm{m})$, and $L$ is the length $(\mathrm{m})$ of the canal pool. There is a constant level reservoir at the upstream end. It is connected with a sluice gate to the canal. Altogether the canal contains four operative motorized sluice gates, therefore it is possible to divide it into four pools. There is a sharp-crested weir with variable height at the downstream end. The same structures are found at the downstream end of every pool to model the gravity offtakes for irrigation (with minimum height of $34.3 \mathrm{~cm}$ ). The maximum discharge that can circulate is $150 \mathrm{~L} / \mathrm{s}$.

There are nine pressure sensors that are used to measure the water levels. The data from the water level and gate opening measurement are connected to a supervisory control and data acquisition system (SCADA). The SCADA system was developed in MATLAB and Simulink environment, which makes straightforward the test of any control algorithm developed in Embedded MATLAB language (MATLAB 2010).

The UPC-PAC is short, completely affected by backwater. Due to the low friction and zero slope, one wave can travel several times back and forth before it finally dampens. This phenomena is known as resonance. A detailed description of this phenomena can be found in van Overloop et al. (2010a).

More information about the laboratory canal can be found in Sepúlveda (2008).

\section{Modeling}

First the general modeling approach is explained. Then the gate modeling is introduced, followed by the introduction of the particular model. Finally, in the last two parts of this section the state space models are described in detail for each case: using the discharge and the gate opening as control action variable.

\section{General Model of the Canal Pool}

The model for control purposes will be presented in the continuous frequency domain, the Laplace domain (Ogata 2010). All variables are deviations for the nominal variable around a chosen steady state (Table 2). During all the experiments this linearization is used. Hence the relative water level, hereinafter referred to as water level, is equal to
Table 2. Steady State at the Beginning and End of the Experiments

\begin{tabular}{lc}
\hline Parameter & Value \\
\hline$Q_{\text {appr }}$ & $60 \mathrm{~L} / \mathrm{s}$ \\
Sp1 & $85 \mathrm{~cm}$ \\
Sp2 & $70 \mathrm{~cm}$ \\
Sp3 & $55 \mathrm{~cm}$ \\
G1 & $7.4 \mathrm{~cm}$ \\
G3 & $12.6 \mathrm{~cm}$ \\
G5 & $11.8 \mathrm{~cm}$ \\
W4 & $35 \mathrm{~cm}$ \\
\hline
\end{tabular}

$$
h_{i}(t)=H_{i}(t)-H_{0 i}
$$

where $H_{i}=$ absolute water level; $H_{0 i}=$ nominal water level belonging to the steady state shown in Table 2 ; and $h_{i}=$ relative water level that is going to be used. Subsequently, the quantities relative to the steady state will be noted with lower case letters. If not stated otherwise, these relative quantities will be discussed.

In order to construct the state space model from the gate models and the models of the canal pool described in the Laplace domain, the following transfer functions are needed, where $s$ is the Laplace operator:

1. From the upstream water level to the upstream discharge $p_{11}(s)=\left[h_{u i}(z)\right] /\left[q_{i}(s)\right]$

2. From the upstream water level to the downstream discharge $p_{12}(s)=-\left[h_{u i}(z)\right] /\left[q_{i+1}(s)\right]$;

3. From the downstream water level to the upstream discharge $p_{21}(s)=\left[h_{i}(z)\right] /\left[q_{i}(s)\right]$; and

4. From the downstream water level to the downstream discharge $p_{22}(s)=-\left[h_{i}(s)\right] /\left[q_{i+1}(s)\right]$ where $h_{i}=$ downstream and $h_{u i}=$ upstream water level, and $q_{i}=$ upstream and $q_{i+1}=$ downstream discharge (Fig. 1).

The last two items can also be used to model the disturbances (offtakes at the downstream end of the canal). The transfer functions can be summarized in matrix form

$$
\left(\begin{array}{c}
h_{u i}(s) \\
h_{i}(s)
\end{array}\right)=\left[\begin{array}{ll}
p_{11}(s) & p_{12}(s) \\
p_{21}(s) & p_{22}(s)
\end{array}\right]\left(\begin{array}{c}
q_{i}(s) \\
q_{i+1}(s)
\end{array}\right)
$$

These transfer functions can be obtained by system identification (Weyer 2001) or by using any simplified hydraulic model. Some examples are integrator delay (ID) (Schuurmans et al. 1995) or integrator delay zero (IDZ) (Litrico and Fromion 2004). The UPC-PAC has significant resonance. The problem of resonance of canal pools is first dealt with in Schuurmans (1997) and later in van Overloop (2006). In van Overloop et al. (2010a), a model was developed especially for resonant canals, which is used in this paper. The detailed modeling can be found in Horváth (2013).

\section{Integrator Resonance Model}

The intergrator resonance model was developed in van Overloop et al. (2010a) and first applied in van Overloop et al. (2014).

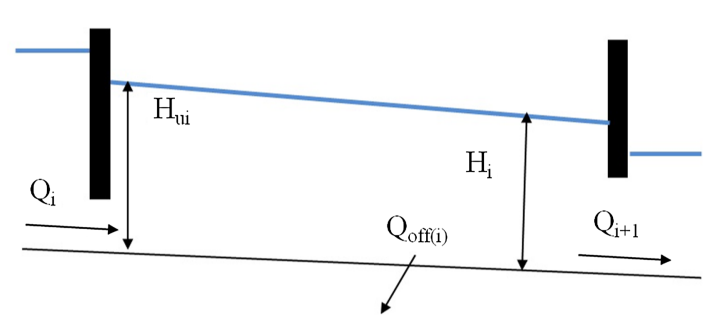

Fig. 1. Schematic view of a canal pool 
The basic idea of the integrator resonance (IR) model is that the transfer function between the downstream water level and the upstream discharge $H_{\mathrm{IR}}(s)$, that is $p_{21}$ in the matrix formulation of Eq. (2), is a third-order system: a second-order function with resonance (underdamped) and an integrator

$$
H_{\mathrm{IR}}(s)=\overbrace{\frac{1}{A_{s} \cdot s}}^{\text {Integrator }} \cdot \overbrace{\frac{\omega_{0}^{2}}{s^{2}+2 \cdot \zeta \cdot \omega_{0} s+\omega_{0}^{2}}}^{\text {Resonance }}
$$

The parameters of the transfer function-the frequency $\left(\omega_{0}\right)$, the damping $(\zeta)$, and the resonance peak $(M)$ —can be expressed as

$$
\begin{gathered}
\omega_{0}=\sqrt{\frac{8 g H_{0}}{X^{2}}} \\
\zeta=\frac{\sqrt{2 g} Q_{0} X}{4 C_{z 0}^{2} R_{0} T_{0} H_{0}^{2 / 3}} \\
M\left(\omega_{0}\right)=\left|\frac{\frac{8 g H_{0}}{T_{0} X^{3}}}{-j \omega_{0}^{3}-\frac{2 g Q_{0}}{C_{z 0}^{2} R_{0} H_{0}} \omega_{0}^{2}+\frac{8 g H}{X^{2}} j \omega_{0}}\right|=\frac{C_{z 0}^{2} R_{0} H_{0}}{2 g Q_{0} X}
\end{gathered}
$$

where $H_{0}=$ reference water level; $g=$ acceleration of gravity; $X=$ length of the canal pool; $Q_{0}=$ reference discharge; $C_{z 0}=$ celerity; $R_{0}=$ hydraulic radius; and $T_{0}=$ top width. Using Eqs. (4)-(6), the downstream $h_{i}(s)$ and upstream $h_{u i}(s)$ water levels can be expressed as

$$
\begin{aligned}
h_{i}(s)= & \frac{1}{A_{s} s} \frac{\omega_{0}^{2}}{s^{2}+2 \zeta \omega_{0} s+\omega_{0}^{2}} q_{i}(s) \\
& -\frac{1}{0.5 A_{s} s}\left(1-\frac{\omega_{0}^{2} 2}{s^{2}+2 \zeta \omega_{0} s+\omega_{0}^{2}}\right) q_{i+1}(s)+\frac{Q_{0}^{2}}{A_{s}^{2} M_{r}} s^{2} \\
& +2 \zeta \omega_{0} s+\omega_{0}^{2} \\
h_{u i}(s)= & \frac{1}{0.5 A_{s} s}\left(1-\frac{\omega_{0}^{2} 2}{s^{2}+2 \zeta \omega_{0} s+\omega_{0}^{2}}\right) q_{i}(s) \\
& +\frac{1}{A_{s} s} \frac{\omega_{0}^{2}}{s^{2}+2 \zeta \omega_{0} s+\omega_{0}^{2}} q_{i+1}(s)+\frac{Q_{0}^{2}}{A_{s}^{2} M_{r}} s^{2}+2 \zeta \omega_{0} s \\
& +\omega_{0}^{2}
\end{aligned}
$$

The parameters in these equations can be calculated or obtained by identification experiments described in Clemmens et al. (2012) and improved in van Overloop and Bombois (2012). In this paper the resonance characteristics were calculated as detailed in Clemmens et al. (2012). The numerical values are summarized in Table 3.

\section{Gate Modeling}

In the previous sections models were obtained between the discharges and the water levels. In order to include the gate opening in the state spaces, the gates have to be modeled. Here, as they

Table 3. Calculated Parameters of the IR Model of the UPC-PAC

\begin{tabular}{lcccc}
\hline $\begin{array}{c}\text { Backwater } \\
\text { Prea } A_{s}\left(\mathrm{~m}^{2}\right)\end{array}$ & $\begin{array}{c}\text { Travel } \\
\text { time } T_{R}(\mathrm{~s})\end{array}$ & $\begin{array}{c}\text { Resonance } \\
\text { frequency } \omega_{\boldsymbol{R}}(\mathrm{rad} / \mathrm{s})\end{array}$ & $\begin{array}{c}\text { Resonance } \\
\text { peak } M_{R}\left(\mathrm{~s} / \mathrm{m}^{2}\right)\end{array}$ \\
\hline 1 & 37.5 & 60 & 0.105 & 5.46 \\
2 & 37.8 & 75 & 0.084 & 3.39 \\
3 & 19.1 & 38 & 0.167 & 1.45 \\
\hline
\end{tabular}

always work under submerged flow conditions, they are modeled by the classical submerged gate equation

$$
Q(t)=C_{d} L(t) B \sqrt{2 g\left[H_{1}(t)-H_{2}(t)\right]}
$$

where $Q=$ discharge under the gate; $C_{d}=$ discharge coefficient; $L=$ gate opening; $B=$ width of the gate; $g=$ acceleration of gravity; $H_{1}=$ water level upstream; and $H_{2}=$ water level downstream. The variables used for the gate modeling are shown in Fig. 2. This equation can be linearized around the steady state $Q_{0}, L_{0}$, $H_{10}, H_{20}$

$$
q_{i}(t)=k_{l i}(t) l_{i}(t)+k_{h i}(t) h_{(i-1)}(t)+k_{h u i}(t) h_{u i}(t)
$$

where $q_{i}=$ upstream discharge of the $i$ th pool; $l_{i}=$ gate opening of the gate at the upstream end of the $i$ th pool; $h_{(i-1)}=$ downstream water level of the canal pool upstream of the given pool [that is, the $(i-1)$ th pool]; and $h_{u i}=$ upstream water level of pool $i$. Variables $k_{l i}, k_{h i}$, and $k_{h u i}$ are the corresponding coefficients obtained during the linearization. The coefficients of the linear gate equation are time dependent. This indicates that the gate equation is linearized at every control time step.

\section{State Space Formulation}

For both models the state space is constructed in the following discrete form:

$$
\mathbf{x}(k+1)=\mathbf{A}(k) \mathbf{x}(k)+\mathbf{B}(k) u(k)+\mathbf{B}_{d}(k) \mathbf{d}(k)
$$

where $\mathbf{x}($ size $n \times 1)=$ state vector; $u($ size $m \times 1)=$ control action variable; and $\mathbf{d}=$ disturbance vector containing the known changes, the discharge and setpoint changes. Matrices $\mathbf{A}(n \times n), \mathbf{B}(n \times m)$, and $\mathbf{B}_{d}\left(n \times n_{b d}\right)$ are calculated from the given transfer functions depending on the model; their calculation will be explained one by one for each case. Variable $n$ is the number of the states, $m$ is the number of the inputs, and $n_{b d}$ is the number of disturbances. The time step of the discretization is $10 \mathrm{~s}$.

\section{State Space Formulation of Model 1: Using Discharge as Control Action Variable}

In the following the construction of the state space for Model 1, that is, when discharge is the control action variable, is detailed. The transfer function expressing the downstream water level [Eq. (7)] is discretized using zero-order hold sampling. The resulting equation in the $z$ domain has the form as

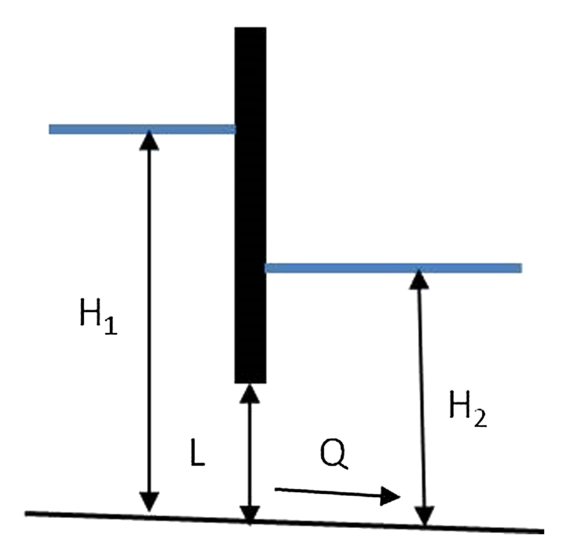

Fig. 2. Variables for one sluice gate 


$$
\begin{aligned}
h_{i}= & \frac{p_{a} z^{2}+p_{b} z^{1}+p_{c}+p_{d} z^{-1}}{z^{3}+p_{e} z^{2}+p_{f} z+p_{g}} q_{i}-\frac{p_{h} z^{2}+p_{i}^{1} z+p_{j}+p_{k} z^{-1}}{z^{3}+p_{e} z^{2}+p_{f} z+p_{g}} q_{i+1} \\
& -\frac{p_{h} z^{2}+p_{i}^{1} z+p_{j}+p_{k} z^{-1}}{z^{3}+p_{e} z^{2}+p_{f} z+p_{g}} q_{\mathrm{off} i}+\frac{p_{l}}{z^{3}+p_{e} z^{2}+p_{f} z+p_{g}}
\end{aligned}
$$

where $h_{i}=$ downstream water level; $q_{i}=$ upstream discharge; and $q_{i+1}=$ downstream discharge of the canal pool. Variable $q_{\text {off } i}$ is the discharge of an offtake located downstream, therefore the transfer function for the offtake discharge is the same as the transfer function for the downstream discharge. The coefficients $p_{a}, p_{b}, p_{c}, p_{d}, p_{e}, p_{f}, p_{g}, p_{h}, p_{i}, p_{j}, p_{k}$ are obtained from the discretization of the IR model for the downstream water level, shown in Eq. (7). The values of these coefficients for the UPC-PAC are shown in the Appendix.

In order to be able to develop the minimization for the water level deviation from the set point, the state space containing the water level error is used instead of the water level

$$
e_{i}(k)=h_{i}(k)-h_{\mathrm{sp} i}(k)
$$

where $h_{\mathrm{sp} i}=$ set point of the $i$ th pool. Applying the inverse $z$-transform, Eq. (12) can be written in the discrete time domain; combined with Eq. (13) the water level error can be expressed as

$$
\begin{aligned}
e_{i}(k+1)= & -p_{e i} e(k)-p_{f i} e_{i}(k-1)-p_{g i} e_{i}(k-2)-h_{i \mathrm{sp}}(k+1) \\
& -p_{e i} h_{\mathrm{sp} i}(k)-p_{f i} h_{\mathrm{sp} i}(k-1)-p_{g i} h_{\mathrm{spi} i}(k-2) \\
& +p_{a i} q_{i}(k)+p_{b i} q_{i}(k-1)+p_{c i} q_{i}(k-2) \\
& +p_{d i} q_{i}(k-3)-p_{h i} q_{i+1}(k)-p_{i i} q_{i+1}(k-1) \\
& -p_{j i} q_{i+1}(k-2)-p_{k i} q_{i+1}(k-3)-p_{h i} q_{\mathrm{off} i}(k) \\
& -p_{i i} q_{\mathrm{off} i}(k-1)-p_{j i} q_{\mathrm{off} i}(k-2)-p_{k i} q_{\mathrm{off} i}(k-3) \\
& +p_{l i}
\end{aligned}
$$

Now the matrices in Eq. (11) can be constructed using Eq. (14). Here they are shown for one canal pool, but they can be generalized to any number of canal pools.

The state vector contains the discharges and water level errors

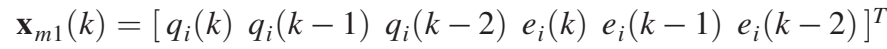

The control action variable is the discharge

$$
u_{m 1}(k)=\Delta q_{i}(k)
$$

where $\Delta q_{i}(k)=$ change in discharge and can be written as

$$
q_{i}(k+1)=q_{i}(k)+\Delta q_{i}(k)
$$

Using Eqs. (14) and (17), the matrices of Eq. (11) are

$$
\mathbf{A}_{m 1}=\left[\begin{array}{cccccc}
1 & 0 & 0 & 0 & 0 & 0 \\
1 & 0 & 0 & 0 & 0 & 0 \\
0 & 1 & 0 & 0 & 0 & 0 \\
p_{a i} & p_{b i} & p_{c i} & -p_{d i} & -p_{e i} & -p_{f i} \\
0 & 0 & 0 & 1 & 0 & 0 \\
0 & 0 & 0 & 0 & 1 & 0
\end{array}\right]
$$

$$
\begin{aligned}
& \mathbf{B}_{m 1}=\left[\begin{array}{llllll}
1 & 0 & 0 & 0 & 0 & 0
\end{array}\right]^{T} \\
& \mathbf{B}_{d m 1}=\left[\begin{array}{cccccccc}
0 & 0 & 0 & 0 & 0 & 0 & 0 & 0 \\
0 & 0 & 0 & 0 & 0 & 0 & 0 & 0 \\
0 & 0 & 0 & 0 & 0 & 0 & 0 & 0 \\
0 & -p_{g i} & -p_{h i} & -p_{i i}-1 & -p_{d i} & -p_{e i} & -p_{f i} \\
0 & 0 & 0 & 0 & 0 & 0 & 0 & 0 \\
0 & 0 & 0 & 0 & 0 & 0 & 0 & 0
\end{array}\right] \\
& \mathbf{d}_{m 1}(k)=\left[q_{\mathrm{off} i}(k+1) q_{\mathrm{off} i}(k) \quad q_{\mathrm{off} i}(k-1) \quad q_{\mathrm{off} i}(k-2)\right. \\
& \left.\times h_{\mathrm{sp} i}(k+1) h_{\mathrm{sp} i}(k) h_{\mathrm{sp} i}(k-1) h_{\mathrm{sp} i}(k-2)\right]^{T}
\end{aligned}
$$

The disturbance matrix $\mathbf{d}_{m 1}$ contains the known disturbances; $q_{\text {off } i}$ is the offtake discharge and $h_{\mathrm{sp} i}$ is the set point of the $i$ th pool. The numerical value of the coefficients is shown in the Appendix.

\section{State Space Formulation of Model 2: Using Gate Opening as Control Action Variable}

While in the formulation of the state space of Model 1 where the discharge is the control action variable only Eq. (7) is used, in this case two more equations are needed: one expressing the upstream water level in a canal pool [Eq. (8)] and the gate Eq. (10).

As before, all these equations are discretized using zero-order hold sampling. The discretized form of Eq. (7) is the same as Eq. (12) in the previous section. The discretized form of the gate equation is the following:

$$
\begin{aligned}
q_{i}(k+1)= & k_{l i} l_{i}(k+1)+k_{h 1 i} h_{u i}(k)+k_{h 2 i} h_{s p i-1}(k) \\
& +k_{h 2 i} e_{i-1}(k)
\end{aligned}
$$

where $i=$ number of the canal pool. In order to obtain the discrete representation of the equation of the upstream water level, Eq. (8) is discretized as

$$
\begin{aligned}
h_{u i}(k+1)= & -p_{e i} h_{u i}(k)-p_{f i} h_{u i}(k-1)-p_{g i} h_{u i}(k-2) \\
& +p_{m i} q_{i}(k)+p_{n i} q_{i}(k-1)+p_{o i} q_{i}(k-2) \\
& +p_{p i} q_{i}(k-3)-p_{q i} q_{i+1}(k)-p_{r i} q_{i+1}(k-1) \\
& -p_{s i} q_{i+1}(k-2)-p_{t i} q_{i+1}(k-3)-p_{q i} q_{\mathrm{off} i}(k) \\
& -p_{r i} q_{\mathrm{off} i}(k-1)-p_{s i} q_{\mathrm{off} i}(k-2)-p_{t i} q_{\mathrm{off} i}(k-3) \\
& +p_{u i}
\end{aligned}
$$

where $p_{m}, p_{n}, p_{o}, p_{p}, p_{q}, p_{r}, p_{s}, p_{t}$ coefficients are obtained from the IR model. The numerical value of the coefficients is shown in the Appendix.

A state space model can be constructed in the form of Eq. (11). The matrices are explained for a two-pool canal; the formulation for a three-pool canal is similar. Now the state additional to the state in Model 1 Eq. (15) contains the water levels in the upstream and of the downstream pool and the gate openings 


$$
\mathbf{x}_{m 2}(k)=\left[\begin{array}{c}
q_{1}(k) \\
q_{1}(k-1) \\
q_{1}(k-2) \\
q_{1}(k-3) \\
e_{1}(k) \\
e_{1}(k-1) \\
e_{1}(k-2) \\
h_{u 1}(k) \\
h_{u 1}(k-1) \\
h_{u 1}(k-2) \\
l_{1}(k) \\
q_{2}(k) \\
q_{2}(k-1) \\
q_{2}(k-2) \\
q_{2}(k-3) \\
e_{2}(k) \\
e_{2}(k-1) \\
e_{2}(k-2) \\
h_{u 2}(k) \\
h_{u 2}(k-1) \\
h_{u 2}(k-2) \\
l_{2}(k)
\end{array}\right]
$$

As for Model 1, the control action variable is also incremental

$$
\mathbf{u}_{m 2}(k)=\left[\begin{array}{ll}
\Delta l_{1}(k) & \Delta l_{2}(k)
\end{array}\right]^{T}
$$

where $\Delta l_{i}(k)=$ change in gate opening and can be written as

$$
l_{i}(k+1)=l_{i}(k)+\Delta l_{i}(k)
$$

The state matrix $\mathbf{A}_{m 2}$ is detailed in blocks

$$
\begin{aligned}
& \mathbf{A}_{m 2}(k)=\left[\begin{array}{ll}
\mathbf{A}_{m 211} & \mathbf{A}_{m 212} \\
\mathbf{A}_{m 221} & \mathbf{A}_{m 222}
\end{array}\right] \\
& \mathbf{A}_{m 211}(k)=\left[\begin{array}{ccccccccccc}
0 & 0 & 0 & 0 & 0 & 0 & 0 & 0 & 0 & 0 & k_{l 1} \\
1 & 0 & 0 & 0 & 0 & 0 & 0 & 0 & 0 & 0 & 0 \\
0 & 1 & 0 & 0 & 0 & 0 & 0 & 0 & 0 & 0 & 0 \\
0 & 0 & 1 & 0 & 0 & 0 & 0 & 0 & 0 & 0 & 0 \\
p_{a 1} & p_{b 1} & p_{c 1} & p_{d 1} & -p_{e 1} & -p_{f 1} & -p_{g 1} & 0 & 0 & 0 & 0 \\
0 & 0 & 0 & 0 & 1 & 0 & 0 & 0 & 0 & 0 & 0 \\
0 & 0 & 0 & 0 & 0 & 1 & 0 & 0 & 0 & 0 & 0 \\
p_{m 1} & p_{n 1} & p_{o 1} & p_{p 1} & 0 & 0 & 0 & -p_{e 1} & -p_{f 1} & -p_{g 1} & 0 \\
0 & 0 & 0 & 0 & 0 & 0 & 0 & 1 & 0 & 0 & 0 \\
0 & 0 & 0 & 0 & 0 & 0 & 0 & 0 & 1 & 0 & 0 \\
0 & 0 & 0 & 0 & 0 & 0 & 0 & 0 & 0 & 0 & 1
\end{array}\right] \\
& \mathbf{A}_{m 212}(k)=\left[\begin{array}{ccccccccccc}
0 & 0 & 0 & 0 & 0 & 0 & 0 & 0 & 0 & 0 & 0 \\
0 & 0 & 0 & 0 & 0 & 0 & 0 & 0 & 0 & 0 & 0 \\
0 & 0 & 0 & 0 & 0 & 0 & 0 & 0 & 0 & 0 & 0 \\
0 & 0 & 0 & 0 & 0 & 0 & 0 & 0 & 0 & 0 & 0 \\
-p_{h 1} & -p_{i 1} & -p_{j 1} & -p_{k 1} & 0 & 0 & 0 & 0 & 0 & 0 & 0 \\
0 & 0 & 0 & 0 & 0 & 0 & 0 & 0 & 0 & 0 & 0 \\
0 & 0 & 0 & 0 & 0 & 0 & 0 & 0 & 0 & 0 & 0 \\
-p_{q 1} & -p_{r 1} & -p_{s 1} & -p_{t 1} & 0 & 0 & 0 & 0 & 0 & 0 & 0 \\
0 & 0 & 0 & 0 & 0 & 0 & 0 & 0 & 0 & 0 & 0 \\
0 & 0 & 0 & 0 & 0 & 0 & 0 & 0 & 0 & 0 & 0 \\
0 & 0 & 0 & 0 & 0 & 0 & 0 & 0 & 0 & 0 & 0
\end{array}\right]
\end{aligned}
$$




$$
\begin{aligned}
& \mathbf{A}_{m 221}(k)=\left[\begin{array}{ccccccccccc}
0 & 0 & 0 & 0 & k_{h 12} & 0 & 0 & 0 & 0 & 0 & 0 \\
0 & 0 & 0 & 0 & 0 & 0 & 0 & 0 & 0 & 0 & 0 \\
0 & 0 & 0 & 0 & 0 & 0 & 0 & 0 & 0 & 0 & 0 \\
0 & 0 & 0 & 0 & 0 & 0 & 0 & 0 & 0 & 0 & 0 \\
0 & 0 & 0 & 0 & 0 & 0 & 0 & 0 & 0 & 0 & 0 \\
0 & 0 & 0 & 0 & 0 & 0 & 0 & 0 & 0 & 0 & 0 \\
0 & 0 & 0 & 0 & 0 & 0 & 0 & 0 & 0 & 0 & 0 \\
0 & 0 & 0 & 0 & 0 & 0 & 0 & 0 & 0 & 0 & 0 \\
0 & 0 & 0 & 0 & 0 & 0 & 0 & 0 & 0 & 0 & 0 \\
0 & 0 & 0 & 0 & 0 & 0 & 0 & 0 & 0 & 0 & 0 \\
0 & 0 & 0 & 0 & 0 & 0 & 0 & 0 & 0 & 0 & 0
\end{array}\right] \\
& \mathbf{A}_{m 222}(k)=\left[\begin{array}{ccccccccccc}
0 & 0 & 0 & 0 & 0 & 0 & 0 & k_{h 22} & 0 & 0 & k_{l 2} \\
1 & 0 & 0 & 0 & 0 & 0 & 0 & 0 & 0 & 0 & 0 \\
0 & 1 & 0 & 0 & 0 & 0 & 0 & 0 & 0 & 0 & 0 \\
0 & 0 & 1 & 0 & 0 & 0 & 0 & 0 & 0 & 0 & 0 \\
p_{a 2} & p_{b 2} & p_{c 2} & p_{d 2} & -p_{e 2} & -p_{f 2} & -p_{g 2} & 0 & 0 & 0 & 0 \\
0 & 0 & 0 & 0 & 1 & 0 & 0 & 0 & 0 & 0 & 0 \\
0 & 0 & 0 & 0 & 0 & 1 & 0 & 0 & 0 & 0 & 0 \\
p_{m 2} & p_{n 2} & p_{o 2} & p_{p 2} & 0 & 0 & 0 & -p_{e 2} & -p_{f 2} & -p_{g 2} & 0 \\
0 & 0 & 0 & 0 & 0 & 0 & 0 & 1 & 0 & 0 & 0 \\
0 & 0 & 0 & 0 & 0 & 0 & 0 & 0 & 1 & 0 & 0 \\
0 & 0 & 0 & 0 & 0 & 0 & 0 & 0 & 0 & 0 & 1
\end{array}\right]
\end{aligned}
$$

The blocks $\mathbf{A}_{m 212}$ and $\mathbf{A}_{m 221}$ represent the interaction between pools. In the case of Model 1, these blocks were zero, and only the matrix along the diagonal of Eq. (27) was present. Then finally the matrix $\mathbf{B}_{m 2}$ and the matrix for the disturbances $\mathbf{B}_{d m 2}$ is detailed

$$
\mathbf{B}_{m 2}=\left[\begin{array}{cccccccccccccccccccccc}
k_{l 1} & 0 & 0 & 0 & 0 & 0 & 0 & 0 & 0 & 0 & 1 & 0 & 0 & 0 & 0 & 0 & 0 & 0 & 0 & 0 & 0 & 0 \\
0 & 0 & 0 & 0 & 0 & 0 & 0 & 0 & 0 & 0 & 0 & k_{l 1} & 0 & 0 & 0 & 0 & 0 & 0 & 0 & 0 & 0 & 1
\end{array}\right]^{T}
$$

$$
\mathbf{d}_{m 2}(k)=\left[\begin{array}{c}
q_{\mathrm{off} 1}(k+1) \\
q_{\mathrm{off} 1}(k) \\
q_{\mathrm{off} 1}(k-1) \\
q_{\mathrm{off} 1}(k-2) \\
h_{\mathrm{sp} 1}(k+1) \\
h_{\mathrm{sp} 1}(k) \\
h_{\mathrm{sp} 1}(k-1) \\
h_{\mathrm{sp} 1}(k-2) \\
1 \\
q_{\mathrm{off} 2}(k) \\
q_{\mathrm{off} 2}(k+1) \\
q_{\mathrm{off} 2}(k-1) \\
q_{\mathrm{off} 2}(k-2) \\
h_{\mathrm{sp} 2}(k+1) \\
h_{\mathrm{sp} 2}(k) \\
h_{\mathrm{sp} 2}(k-1) \\
h_{\mathrm{sp} 2}(k-2) \\
1
\end{array}\right]
$$




$\mathbf{B}_{d m 2}(k)=\left[\begin{array}{cccccccccccccccccc}0 & 0 & 0 & 0 & 0 & 0 & 0 & 0 & 0 & 0 & 0 & 0 & 0 & 0 & 0 & 0 & 0 & 0 \\ 0 & 0 & 0 & 0 & 0 & 0 & 0 & 0 & 0 & 0 & 0 & 0 & 0 & 0 & 0 & 0 & 0 & 0 \\ 0 & 0 & 0 & 0 & 0 & 0 & 0 & 0 & 0 & 0 & 0 & 0 & 0 & 0 & 0 & 0 & 0 & 0 \\ 0 & 0 & 0 & 0 & 0 & 0 & 0 & 0 & 0 & 0 & 0 & 0 & 0 & 0 & 0 & 0 & 0 & 0 \\ -p_{h 1} & -p_{i 1} & -p_{j 1} & -p_{k 1} & -1 & -p_{e 1} & -p_{f 1} & -p_{g 1} & -p_{l 1} & 0 & 0 & 0 & 0 & 0 & 0 & 0 & 0 & 0 \\ 0 & 0 & 0 & 0 & 0 & 0 & 0 & 0 & 0 & 0 & 0 & 0 & 0 & 0 & 0 & 0 & 0 & 0 \\ 0 & 0 & 0 & 0 & 0 & 0 & 0 & 0 & 0 & 0 & 0 & 0 & 0 & 0 & 0 & 0 & 0 & 0 \\ -p_{q 1} & -p_{r 1} & -p_{s 1} & -p_{t 1} & 0 & 0 & 0 & 0 & p_{u 1} & 0 & 0 & 0 & 0 & 0 & 0 & 0 & 0 & 0 \\ 0 & 0 & 0 & 0 & 0 & 0 & 0 & 0 & 0 & 0 & 0 & 0 & 0 & 0 & 0 & 0 & 0 & 0 \\ 0 & 0 & 0 & 0 & 0 & 0 & 0 & 0 & 0 & 0 & 0 & 0 & 0 & 0 & 0 & 0 & 0 & 0 \\ 0 & 0 & 0 & 0 & 0 & 0 & 0 & 0 & 0 & 0 & 0 & 0 & 0 & 0 & 0 & 0 & 0 & 0 \\ 0 & 0 & 0 & 0 & k_{h 12} & 0 & 0 & 0 & 0 & 0 & 0 & 0 & 0 & 0 & 0 & 0 & 0 & 0 \\ 0 & 0 & 0 & 0 & 0 & 0 & 0 & 0 & 0 & 0 & 0 & 0 & 0 & 0 & 0 & 0 & 0 & 0 \\ 0 & 0 & 0 & 0 & 0 & 0 & 0 & 0 & 0 & 0 & 0 & 0 & 0 & 0 & 0 & 0 & 0 & 0 \\ 0 & 0 & 0 & 0 & 0 & 0 & 0 & 0 & 0 & 0 & 0 & 0 & 0 & 0 & 0 & 0 & 0 & 0 \\ 0 & 0 & 0 & 0 & 0 & 0 & 0 & 0 & 0 & -p_{h 2} & -p_{i 2} & -p_{j 2} & -p_{k 2} & -1 & -p_{e 2} & -p_{f 2} & -p_{g 2} & -p_{l 2} \\ 0 & 0 & 0 & 0 & 0 & 0 & 0 & 0 & 0 & 0 & 0 & 0 & 0 & 0 & 0 & 0 & 0 & 0 \\ 0 & 0 & 0 & 0 & 0 & 0 & 0 & 0 & 0 & 0 & 0 & 0 & 0 & 0 & 0 & 0 & 0 & 0 \\ 0 & 0 & 0 & 0 & 0 & 0 & 0 & 0 & 0 & -p_{q 2} & -p_{r 2} & -p_{s 2} & -p_{t 2} & 0 & 0 & 0 & 0 & p_{u 2} \\ 0 & 0 & 0 & 0 & 0 & 0 & 0 & 0 & 0 & 0 & 0 & 0 & 0 & 0 & 0 & 0 & 0 & 0 \\ 0 & 0 & 0 & 0 & 0 & 0 & 0 & 0 & 0 & 0 & 0 & 0 & 0 & 0 & 0 & 0 & 0 & 0 \\ 0 & 0 & 0 & 0 & 0 & 0 & 0 & 0 & 0 & 0 & 0 & 0 & 0 & 0 & 0 & 0 & 0 & 0\end{array}\right]$

Because all these matrices contain coefficients of the linear gate equation like $k_{l 1}, k_{h 12}, k_{h 12}$, these coefficients are updated at every control time step. Therefore in this formulation the previously written matrices are time dependent.

\section{Comparison of the Two Modeling Approaches in Time Domain}

In order to show the difference between the two approaches, Model 1 discharge as control action variable and Model 2 gate equation incorporated in the state space model, a step response tests is carried out. Two open-loop tests are carried out to see how the two different models respond. Only one movement is carried out in the indicated structure, all the other gates are at rest.

First, the discharge, or in case of Model 2 the corresponding gate opening, is increased for Gate 1. This increase has a step nature, the value is increased and then it stays at that new value. The responses are compared to the numerical solution of the Saint-Venant (SV) equations, solved by the one-dimensional (1D) hydrodynamic simulator simulation of irrigation canals (SIC) (Malaterre and Baume 1997). The result of the test for Model 1 is shown in Fig. 3 and for Model 2 in Fig. 4. As Gate 1 is opened, the water level increased in all the canal pools after a certain time delay. This is shown by the SV model. For Model 1, the increase is only seen in Pool 1, but no effect is seen in the other pools. However, Model 2 reproduced the effect in all the canal pools.

A similar open-loop step response test is carried out but instead of the first gate, the last gate is opened. The response of Model 1 is compared with the SV model response in Fig. 5. Model 1 reproduced the shape and the final value of the step at Pool 3, and the shape of the beginning of the response in Pool 2. However, at Pool 1 it did not show any water level change, while in Fig. 6 Model 2 was able to reproduce the shape of the step response in all the pools.

In both cases, Model 2 is able to represent the interactions between the canal pools better. From this motivation, the use of this model as internal model of centralized MPC is considered.

\section{Control Formulation}

The developement of the model predictive controller is based on Camacho and Bordons (1998) and van Overloop (2006). Using the model from Eq. (11), the following objective function is minimized:

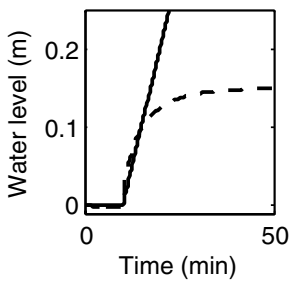

(a)

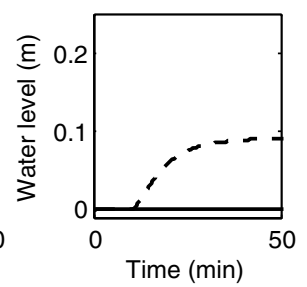

(b)

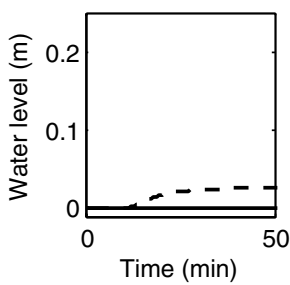

(c)
Fig. 3. Step response of Model 1 to a step at Gate 1, with dashed line the response of the SV equations and with continuous line the response of the IR model: (a) Pool 1; (b) Pool 2; (c) Pool 3

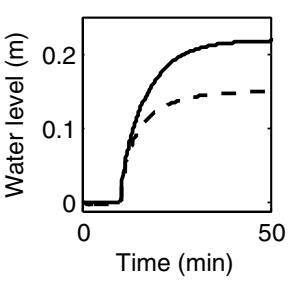

(a)

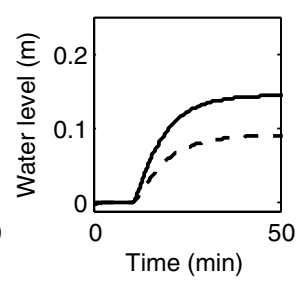

(b)

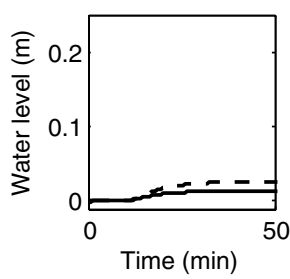

(c)
Fig. 4. Step response of Model 2 to a step at Gate 1, with dashed line the response of the SV equations and with continuous line the response of the IR model: (a) Pool 1; (b) Pool 2; (c) Pool 3 


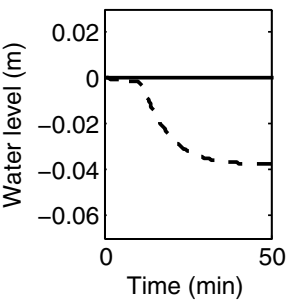

(a)

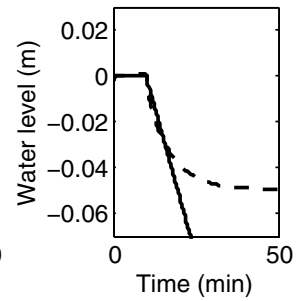

(b)

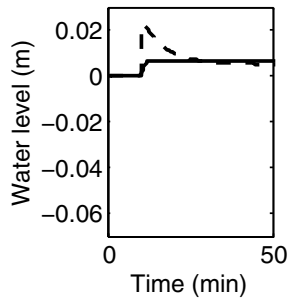

(c)
Fig. 5. Step response of Model 1 to a step at Gate 3, with dashed line the response of the SV equations and with continuous line the response of the IR model: (a) Pool 1; (b) Pool 2; (c) Pool 3

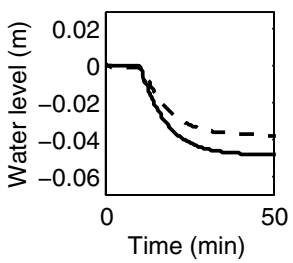

(a)

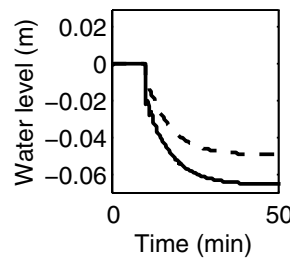

(b)

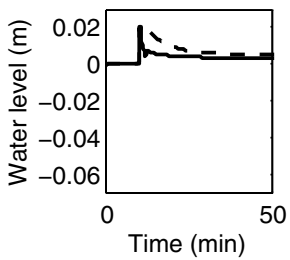

(c)
Fig. 6. Step response of Model 2 to a step at Gate 3, with dashed line the response of the SV equations and with continuous line the response of the IR model: (a) Pool 1; (b) Pool 2; (c) Pool 3

$$
\begin{gathered}
\min _{\mathbf{U}} J=\sum_{j=1}^{\lambda} x(k+j \mid k)^{T} P_{j} x(k+j \mid k) \\
+\sum_{j=0}^{\lambda-1} u(k+j \mid k)^{T} R_{j} u(k+j \mid k) \quad x_{\min }<x<x_{\max } \\
u_{\min }<u<u_{\max }
\end{gathered}
$$

where $\mathbf{U}=$ control action during all the prediction horizon $(\lambda)$

$$
\mathbf{U}=\left[\begin{array}{c}
u(k \mid k) \\
u(k+1 \mid k) \\
u(k+2 \mid k) \\
\cdots \\
\cdots \\
u(k+\lambda-1 \mid k)
\end{array}\right]
$$

$\mathbf{P}_{j}^{n \times n}$ and $\mathbf{R}_{j}^{m \times m}$ matrices such that

$$
\begin{aligned}
& \mathbf{P}_{j}=\left[\begin{array}{cccc}
p_{1} & 0 & 0 & 0 \\
0 & p_{2} & 0 & 0 \\
0 & 0 & \ldots & 0 \\
0 & 0 & 0 & p_{n}
\end{array}\right] \\
& \mathbf{R}_{j}=\left[\begin{array}{cccc}
r_{1} & 0 & 0 & 0 \\
0 & r_{2} & 0 & 0 \\
0 & 0 & \ldots & 0 \\
0 & 0 & 0 & r_{m}
\end{array}\right]
\end{aligned}
$$

In this paper all weighing matrices $\mathbf{P}_{j}$ and $\mathbf{R}_{j}$ are chosen to be equal and diagonal, $\mathbf{P}_{j}=\mathbf{P}$ for $j=1,2, \ldots, \lambda$ and $\mathbf{R}_{j}=\mathbf{R}$ for $j=0,1, \ldots, \lambda-1$. In other words, the weights of the optimization do not change during the prediction horizon. The matrix $\mathbf{R}$ contains the corresponding weights to the input, the matrix $\mathbf{P}$ contains the weights on the state. In this case the input is the change in discharge, therefore matrix $\mathbf{R}$ penalizes the changes in discharge.
Table 4. Tuning Parameters of the Controllers eMAVE and duMAVE

\begin{tabular}{lcc}
\hline Test name & eMAVE & duMAVE \\
\hline Set point change-discharge & 0.03 & 0.01 \\
Disturbances—discharge & 0.03 & 0.03 \\
Set point change-gate opening & 0.03 & 0.015 \\
Disturbances_gate opening & 0.03 & 0.009 \\
\hline
\end{tabular}

Note: duMAVE = maximum allowed value estimate for the control action variable; $\mathrm{eMAVE}=$ maximum allowed value estimate for the water level error.

Table 5. Summary of the Four Tests

\begin{tabular}{lcc}
\hline Known or unknown & Set point change & Disturbance \\
\hline Known & Test 1 & Test 2 \\
Unknown & Test 3 & Test 4 \\
\hline
\end{tabular}

Matrix $\mathbf{P}$ penalizes the state. The authors chose to penalize the current water level error $\left[e_{i}(k)\right]$, therefore only the diagonal elements of $\mathbf{P}$ corresponding to the current water levels in the state are nonzero. The weights on the water level error and change in discharge are chosen using Bryson's rule (Bryson and Ho 1969): the weights are the reciprocals of the squares of the maximum allowed values. For example, if the maximum allowed water level error is chosen to be $3 \mathrm{~cm}(\mathrm{eMAVE}=0.03 \mathrm{~m})$, then the corresponding entry of the weighing matrix $\mathbf{P}$ can be expressed as

$$
p_{i}=\frac{1}{\mathrm{eMAVE}^{2}}
$$

The penalties for the change in input discharge (the entries of $\mathbf{P}$ ) are expressed in the same way. The weights used for the experiments are summarized in Table 4.

Regarding the tuning of the controllers, it is a challenging task to give fair comparison when tuning is applied. In Malaterre and Baume (1999) different tuning values have been used and the best scenario is selected. In this case the authors decided to use the following methodology to achieve the best performance for the controllers: the error on the water level (eMAVE) was set to be the same for both controllers and the weight on the control action was changed. For the tuning of the weight on the control action variable, numerical experiments have been used. In both cases, the weight was decreased until instability occurred, when visually the control action started to oscillate. The limiting value before these oscillations appeared was used as weight.

\section{Description of the Experiments}

All tests were carried out at the experimental canal, UPC-PAC. The test scenarios are established in order to test the predictive controllers during this work. There are four tests, detailed in Table 5.

All tests start and finish with the steady state conditions shown in Table 2 . The discharge is approximately $\left(Q_{\text {appr }}\right) 60 \mathrm{~L} / \mathrm{s}$. The set point of the water level in the first pool (Sp1) is $85 \mathrm{~cm}$, in the second pool is $70 \mathrm{~cm}(\mathrm{Sp} 2)$, and in the third pool $(\mathrm{Sp} 3)$ is $55 \mathrm{~cm}$. The gate openings are set to achieve the given water levels in each pool, shown in columns Gate 1 (G1), Gate 2 (G2), and Gate 5 (G5). The height of the final weir (W4) was set to $35 \mathrm{~cm}$.

\section{Test 1: Set Point Changes}

This test contains three set point changes: first in Pool 1, then in Pool 2, and finally in Pool 3. In the first two cases the set point 
Table 6. Set Point Change Test

\begin{tabular}{lccccccccc}
\hline $\begin{array}{l}\text { Time } \\
(\mathrm{min})\end{array}$ & $\begin{array}{c}Q_{\mathrm{appr}} \\
\mathrm{L} / \mathrm{s}\end{array}$ & $\begin{array}{c}\mathrm{Sp} 1 \\
(\mathrm{~cm})\end{array}$ & $\begin{array}{c}\mathrm{Sp} 2 \\
(\mathrm{~cm})\end{array}$ & $\begin{array}{c}\mathrm{Sp} 3 \\
(\mathrm{~cm})\end{array}$ & $\begin{array}{c}\mathrm{W} 1 \\
(\mathrm{~cm})\end{array}$ & $\begin{array}{c}Q_{w 1} \\
\mathrm{~L} / \mathrm{s}\end{array}$ & $\begin{array}{c}\mathrm{W} 3 \\
(\mathrm{~cm})\end{array}$ & $\begin{array}{c}Q_{w 3} \\
\mathrm{~L} / \mathrm{s}\end{array}$ & $\begin{array}{c}\mathrm{W} 4 \\
(\mathrm{~cm})\end{array}$ \\
\hline 0 & 60 & 85 & 70 & 55 & 90 & 0 & 90 & 0 & 35 \\
30 & 84 & 85 & 70 & 60 & 90 & 0 & 90 & 0 & 35 \\
60 & 60 & 85 & 70 & 55 & 90 & 0 & 90 & 0 & 35 \\
90 & 60 & 85 & 60 & 55 & 90 & 0 & 90 & 0 & 35 \\
180 & 60 & 85 & 70 & 55 & 90 & 0 & 90 & 0 & 35 \\
210 & 60 & 75 & 70 & 55 & 90 & 0 & 90 & 0 & 35 \\
240 & 60 & 85 & 70 & 55 & 90 & 0 & 90 & 0 & 35 \\
270 & End & - & - & - & - & - & - & - & - \\
\hline
\end{tabular}

changes by $10 \mathrm{~cm}$ and then goes back to the original state, while in the third case the set point changes only $5 \mathrm{~cm}$. These changes are more than $10 \%$ of the water level, hence it is a challenging task for the controller. Table 6 shows the test step by step. The columns Sp show the actual set points, and the columns $W$ and $Q_{w}$ show the properties of the weirs. Variable $Q_{w}$ gives the approximation of the weir discharge, while $W$ gives the height of the weir. In this test all offtakes are closed, the weir height is at its maximum of $90 \mathrm{~cm}$. There is flow only over Weir 4, which is the flow leaving the canal.

\section{Test 2: Unknown Set Point Change}

The set point changes in Test 2 are the same as in Test 1 , but they are unknown for the controller. In case of set point change, unknown means that the set point change is not known beforehand, only at the moment of its occurrence.

\section{Test 3: Reaction to Disturbances}

The disturbance rejection was tested by using the lateral weirs (Table 7). In this test two disturbances are used: first, after 30 min the weir at the downstream end of Pool 1 is opened. After $30 \mathrm{~min}$ more, that is, at $60 \mathrm{~min}$, it is closed and then the system has $30 \mathrm{~min}$ more to recover. After this time, at $90 \mathrm{~min}$, the weir at the end of the second pool is opened for $30 \mathrm{~min}$. The offtake is closed at $120 \mathrm{~min}$ and the test is finished at $150 \mathrm{~min}$. In both cases the offtake discharge is $20 \mathrm{~L} / \mathrm{s}$. This is one-third of the actual discharge (approximately $60 \mathrm{~L} / \mathrm{s}$ ), hence it is a considerable disturbance for the controller to tackle.

\section{Test 4: Unknown Disturbances}

Test 4 is similar to Test 3, but the disturbances are unknown for the controller during all the simulation.

\section{Experimental Results}

The effect of the choice of control action variables for centralized model predictive controller of irrigation canals was investigated. Centralized controllers were developed using both variables and

Table 7. Disturbance Test

\begin{tabular}{lccccccccc}
\hline $\begin{array}{l}\text { Time } \\
(\mathrm{min})\end{array}$ & $\begin{array}{c}Q_{\text {appr }} \\
\mathrm{L} / \mathrm{s}\end{array}$ & $\begin{array}{c}\mathrm{Sp} 1 \\
(\mathrm{~cm})\end{array}$ & $\begin{array}{c}\mathrm{Sp} 2 \\
(\mathrm{~cm})\end{array}$ & $\begin{array}{c}\mathrm{Sp} 3 \\
(\mathrm{~cm})\end{array}$ & $\begin{array}{c}\mathrm{W} 1 \\
(\mathrm{~cm})\end{array}$ & $\begin{array}{r}Q_{w 1} \mathrm{~L} / \mathrm{s} \\
(\mathrm{cm})\end{array}$ & $\begin{array}{r}\mathrm{W} 3 \\
\mathrm{~L} / \mathrm{s}\end{array}$ & $\begin{array}{c}\mathrm{W} 4 \\
(\mathrm{~cm})\end{array}$ \\
\hline 0 & 60 & 85 & 70 & 55 & 90 & 0 & 90 & 0 & 35 \\
30 & 60 & 85 & 70 & 55 & 75 & 20 & 90 & 0 & 35 \\
60 & 60 & 85 & 70 & 55 & 90 & 0 & 90 & 0 & 35 \\
90 & 60 & 85 & 70 & 55 & 90 & 0 & 60 & 20 & 35 \\
120 & 60 & 85 & 70 & 55 & 90 & 0 & 90 & 0 & 35 \\
150 & End & - & - & - & - & - & - & - & - \\
\hline
\end{tabular}

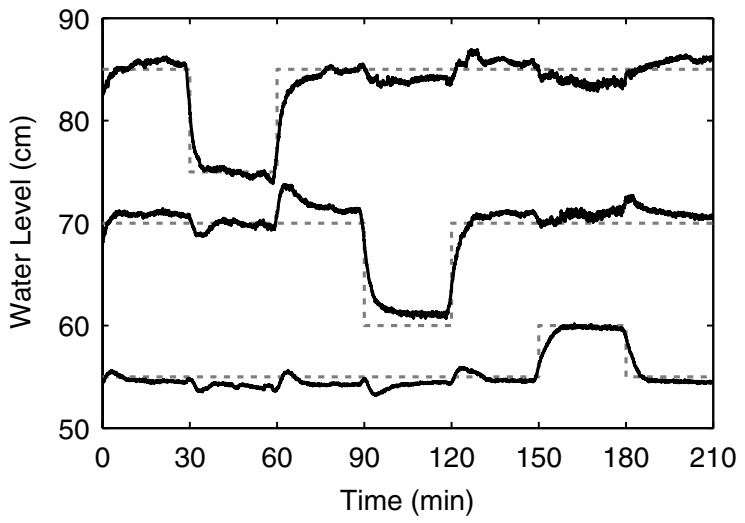

Fig. 7. Known set point change test using discharge as control action variable; the continuous lines are the measured water levels in the three pools, the dashed lines are the set point

tested experimentally using four scenarios: (1) known set point change, (2) unknown set point change, (3) known disturbances, and (4) unknown disturbances. The algorithms were implemented using the SCADA system of the UPC-PAC developed in MATLAB 2010. The plotted water levels are the measurements obtained from the SCADA system during the experiments.

Figs. 7 and 8 show the results of using discharge as control action variable for known set point changes and known disturbances. In both cases the controller performs well, all set points are tracked, and the set points are restored after the known disturbances occurred.

However, for unknown set point change test (Fig. 9) and unknown disturbance test (Fig. 10), this method produces a steady state offset. For the unknown set point change test in Fig. 9, the third set point change is not carried out at all: the water level in Pool 3 should have been $60 \mathrm{~cm}$ (as shown by the dashed line), but the controller was not acting. Similar problems can be seen for the unknown disturbance test in Fig. 10. When the unknown offtake in Pool 1 is open, the water level changes and the controller does not keep it at set point. The same phenomenon can be seen when the offtake is open in Pool 2: neither the water level of Pool 2 nor the water level of Pool 1 is kept at set point.

The same experiments were carried out using the linearized gate equation combined into the state space model. Figs. 11 and 12 show the result for the known changes test. These test results

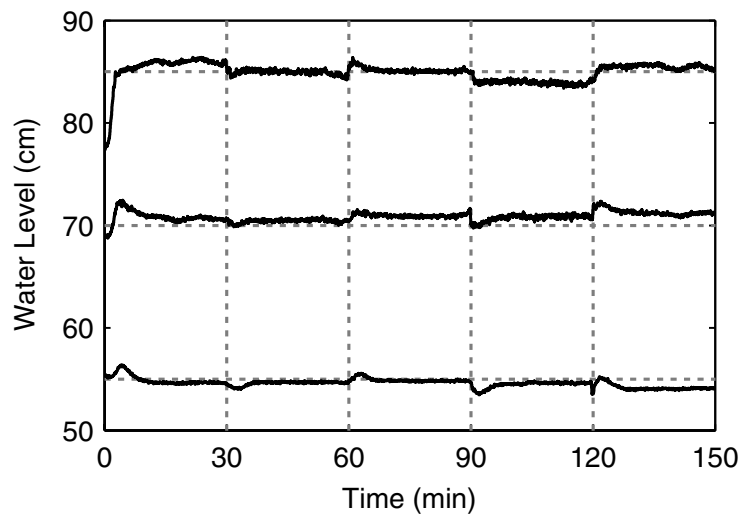

Fig. 8. Known disturbance test using discharge as control action variable; the continuous lines are the measured water levels in the three pools, the horizontal dashed lines are the set point, and the vertical dashed lines are the time when the disturbance occurred is indicated 


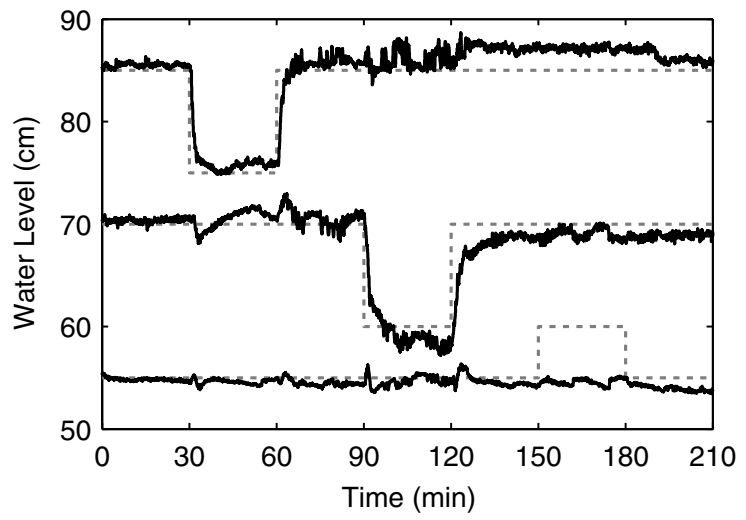

Fig. 9. Unknown set point change test using discharge as control action variable; the continuous lines are the measured water levels in the three pools, the dashed lines are the set point

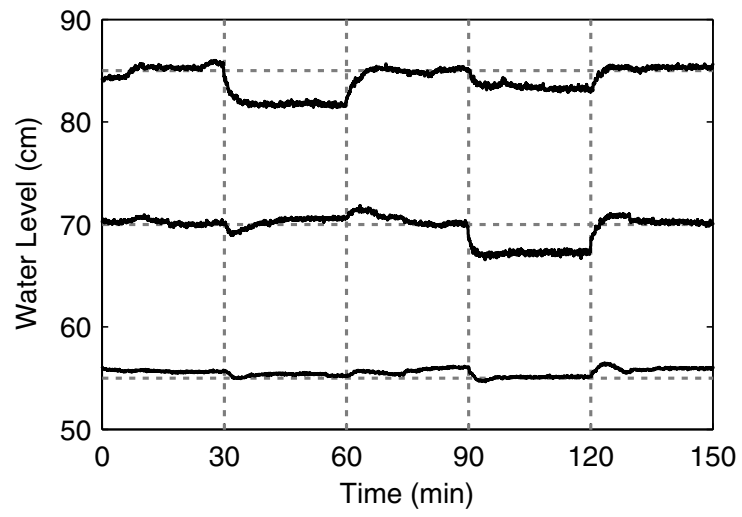

Fig. 10. Unknown disturbance change test using discharge as control action variable; the continuous lines are the measured water levels in the three pools, the horizontal dashed lines are the set point, and the vertical dashed lines are the time when the disturbance occurred is indicated

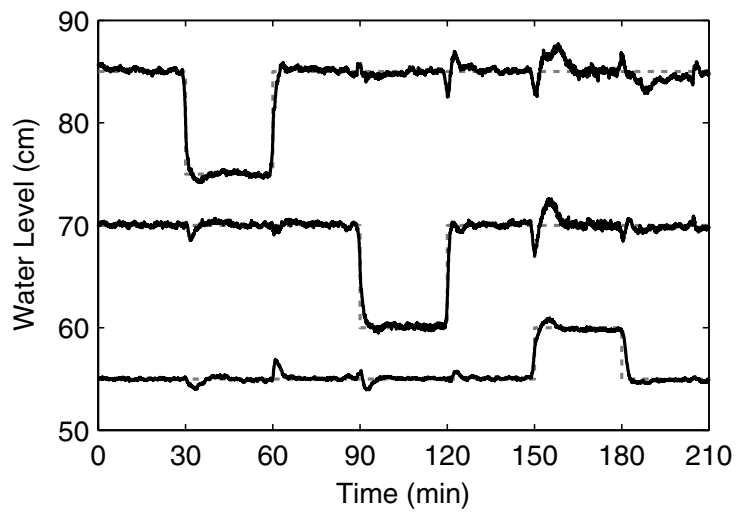

Fig. 11. Known set point change test using gate opening as control action variable; the continuous lines are the measured water levels in the three pools, the dashed lines are the set point

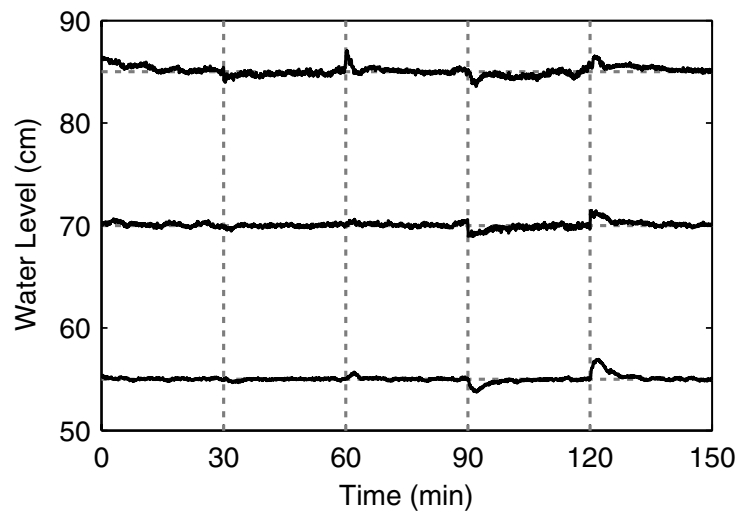

Fig. 12. Known disturbance test using gate opening as control action variable; the continuous lines are the measured water levels in the three pools, the horizontal dashed lines are the set point, and the vertical dashed lines are the time when the disturbance occurred is indicated

do not show considerable differences compared with the method using discharge as control action variable: the set point change tests (Figs. 9 and 11) show similar results. Similar responses can be observed in the known disturbance tests: the results using the discharge as control action variable (Fig. 10) are similar to the results when gate opening is used (Fig. 12).

Comparing the unknown tests, the better performance of the model using the gate openings as control action variable can clearly be noticed. The difference between the set point change test with discharge (Fig. 9) and gate opening (Fig. 13) as control action variable is clearly visible: while the setpoint change in Pool 3 between 150 and 180 min was not carried out at all, the controller using the gate openings was able to carry out the set point change.

Similar advantages can be observed in the comparison of the unknown disturbance test. While the controller having discharge as control action variable (Fig. 10) was not able to maintain the desired setpoints, the controller using the gate opening (Fig. 14) was able to keep the setpoints in all pools: after the disturbances occurred, the water level returned to set point within less than $10 \mathrm{~min}$.

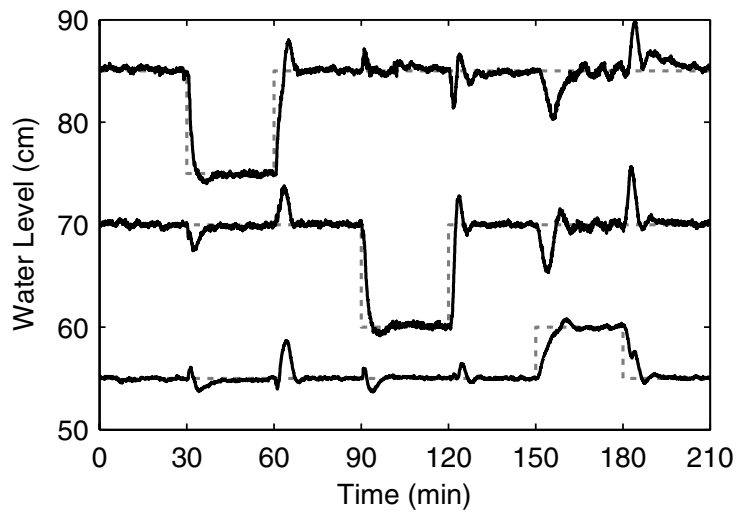

Fig. 13. Unknown set point change test using gate opening as control action variable; the continuous lines are the measured water levels in the three pools, the dashed lines are the set point 


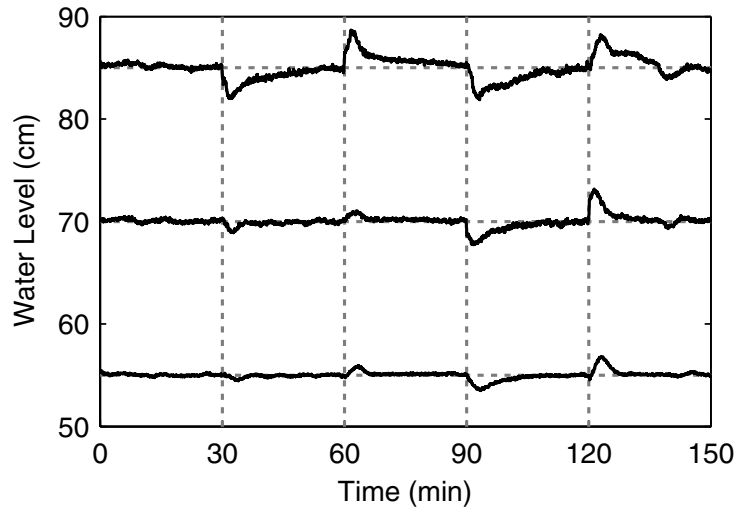

Fig. 14. Unknown disturbance change test using gate opening as control action variable; the continuous lines are the measured water levels in the three pools, the horizontal dashed lines are the set point, and the vertical dashed lines are the time when the disturbance occurred is indicated

\section{Discussion}

Two different approaches for control action variables have been implemented and tested experimentally with centralized model predictive controllers on a canal containing three short pools. During the experiments, in several cases, especially in case of unknown changes, the controller using gate openings have performed better.

Because both the approach of building the state space and tuning the controller are similar, one might conjecture that this difference of performance is due to the use of an internal model that is able to represent better the behavior of the plant. In fact, when the modeling ability of the disturbance propagation was examined in "Description of the Experiments," the model using gate openings performed better: it was able to model the effect of a step not only in the neighboring pool, but also further upstream or downstream. MPC calculates a trajectory of controlled variable during the prediction horizon using the measured values and the internal model. The calculated control action is computed to realize this trajectory. If the internal model describes better the system, the implemented control action more likely yields the desired result.

This might explain the better performance of Model 2 for centralized model predictive control: in this case the controller has more information and it can better approximate the variables over the prediction horizon.

\section{Different Kind of Canal Pools}

In this paper only one type of canal pools is discussed, so-called short canal pools: these are canal pools completely affected by backwater and prone to resonance. The motivation for using the gate openings as control action variables is coming from the interaction between canal pools; by modeling the gates they can be reproduced better. In case of long canal pools, these interactions are less strong. In other words, when a disturbance from downstream might not always reaches the upstream end of each pool, the use of this kind of modeling might not bring so many advantages. Therefore the findings cannot be generalized in a straightforward manner to other types of canal pools.

\section{Relationship between the Results and the Control Configuration}

The presented results and conjectures are valid for centralized configuration. As published in Malaterre and Baume (1999), the effect of the choice of control action variables is different in case of decentralized configuration. What would be the effect in the distributed case cannot be deduced from this study and would be a possible question to study.

\section{Nonlinearity of the Gates}

The use of gate opening as control action variables involves the use of linearized gate equations. The nonlinearity depends on the type of structure and the operation conditions. Here sluice gates were used with a normal operating conditions, which caused the linearized coefficients to vary to a considerable extent. The gate equation is linearized at every control time step, therefore the error due to the nonlinearity only appears in the prediction horizon. The extent of the nonlinearity depends on the type of hydraulic structures and the current conditions. In any event, only the first calculated action of the controller is implemented, then control actions are recalculated again with the new linearized conditions for another prediction horizon.

\section{Conclusions}

In this paper the choice of control action variables for irrigation canals have been analyzed. For decentralized control, the use of discharge as control action variable was suggested by Malaterre and Baume (1999). In this paper the choice of control action variables for centralized control, more specifically centralized model predictive control for short resonant canals, was analyzed. The analysis was supported by experiments on a laboratory canal. Based on the analysis and the experiments, the use of gate opening as control action variable might be more advantageous for this kind of canal pools. In this case, the model for the controller can take into account the interaction between canal pools and this better modeling can improve how the controller can tackle the steady state offset.

Further research can include the investigation into different kind of canal pools having different flow condition and also the choice of control action variables for distributed control.

\section{Appendix. Numerical Values of the Calculated Transfer Functions}

\begin{tabular}{|c|c|c|c|c|c|c|c|c|c|c|c|c|c|c|c|c|c|c|c|c|c|}
\hline Pool & $p_{a}$ & $p_{b}$ & $p_{c}$ & $p_{d}$ & $p_{e}$ & $p_{f}$ & $p_{g}$ & $p_{h}$ & $p_{i}$ & $p_{j}$ & $p_{k}$ & $p_{l}$ & $p_{m}$ & $p_{n}$ & $p_{o}$ & $p_{p}$ & $p_{q}$ & $p_{r}$ & $p_{s}$ & $p_{t}$ & $p_{u}$ \\
\hline 1 & 0.042 & 0.151 & 0.038 & 0.000 & -1.920 & 1.730 & -0.810 & 0.477 & -0.629 & 0.383 & 0.000 & 0.000 & 0.477 & -0.629 & 0.383 & 0.000 & 0.042 & 0.151 & 0.038 & 0.000 & 0.000 \\
\hline 2 & 0.028 & 0.102 & 0.025 & 0.000 & -2.242 & 2.020 & -0.778 & 0.550 & -0.820 & 0.425 & 0.000 & 0.000 & 0.550 & -0.820 & 0.425 & 0.000 & 0.028 & 0.102 & 0.025 & 0.000 & 0.000 \\
\hline 3 & 0.000 & 0.000 & 0.000 & 0.523 & -1.000 & 0.000 & 0.000 & 0.523 & 0.000 & 0.000 & 0.000 & 0.000 & 0.523 & 0.000 & 0.000 & 0.000 & 0.000 & 0.000 & 0.000 & 0.523 & 1.000 \\
\hline
\end{tabular}

Note: Calculated coefficients of the state space models. 


\section{References}

Bryson, A., and Ho, Y. (1969). "Applied optimal control: Optimization, estimation, and control." Blaisdell book in the pure and applied sciences, Blaisdell Publications, Waltham, MA.

Camacho, E. F., and Bordons, C. (1998). Model predictive control, Springer, London.

Clemmens, A., Litrico, X., van Overloop, P.-J., and Strand, R. (2012). "Estimating canal pool resonance with auto tune variation." J. Irrig. Drain. Eng., 10.1061/(ASCE)IR.1943-4774.0000384, 9-15.

Gómez, M., Rodellar, J., and Mantecón, J. A. (2002). "Predictive control method for decentralized operation of irrigation canals." Appl. Math. Modell., 26(11), 1039-1056.

Horváth, K. (2013). "Model predictive control of resonance sensitive irrigation canals.” Ph.D. thesis, Technical Univ. of Catalonia, Barcelona, Spain.

Lemos, J. M., Rato, L. M., Machado, F., Nogueira, N., Salgueiro, P., and Neves-Silva, R. (2007). "Predictive adaptive control of water level in canal pools." Proc., IEEE 16th Int. Conf. on Systems Science, Vol. 3, IEEE, Wrocław, Poland, 139-148.

Li, Y., Cantoni, M., and Weyer, E. (2004). "Design of a centralized controller for an irrigation channel using $H \infty$ loop-shaping." UKACC Control 2004 Mini Symposia 11.1, IET, 7.

Li, Y., and De Schutter, B. (2010). "Control of a string of identical pools using non-identical feedback controllers." Proc., 49th IEEE Conf. on Decision and Control, IEEE, 120-125.

Litrico, X., and Fromion, V. (2004). "Simplified modeling of irrigation canals for controller design.” J. Irrig. Drain. Eng., 10.1061/(ASCE) 0733-9437(2004)130:5(373), 373-383.

Litrico, X., Malaterre, P.-O., Baume, J., and Ribot-Bruno, J. (2008). "Conversion from discharge to gate opening for the control of irrigation canals.” J. Irrig. Drain. Eng., 10.1061/(ASCE)0733-9437(2008)134: 3(305), 305-314.

Maestre Torreblanca, J. M. (2010). "Distributed model predictive control based on game theory." Ph.D. thesis, Univ. of Seville, Seville, Spain.

Malaterre, P.-O., and Baume, J. P. (1997). "SIC 3.0, a simulation model for canal automation design" Int. Workshop on Regulation of Irrigation Canals: State of Art of Research and Applications, A. Mokhlisse, ed., Vol. I, L.A.A.A.-C.N.R.S., Marrakech, Morocco, 68-75.

Malaterre, P.-O., and Baume, J. P. (1999). "Optimum choice of control action variables and linked algorithms. Comparison of different alternatives." Proc., Workshop on Modernization of Irrigation Water Delivery Systems, Committee on Irrigation and Drainage, Denver, CO, 387-406.
MATLAB Version 7.10.0 (R2010a) [Computer software]. MathWorks, Natick, MA.

Montazar, A., van Overloop, P.-J., and Brouwer, R. (2005). "Centralized controller for the Narmada main canal." Irrig. Drain., 54(1), 79-89.

Ogata, K. (2010). Modern control engineering, 5th Ed., Instrumentation and Controls Series, Prentice Hall, Upper Saddle River, NJ.

Rivas-Perez, R., Prada Moraga, C., Peran Gonzalez, J., and Kovalenko, P. (2002). "Robust adaptive predictive control of water distribution in irrigation canals." Proc., 15th Int. Federation of Automatic Control World Congress, Vol. 15, International Federation of Automatic Control.

Schuurmans, J. (1997). "Control of water levels in open channels.” Ph.D. thesis, Delft Univ. of Technology, Delft, The Netherlands.

Schuurmans, J., Bosgra, O., and Brouwer, R. (1995). "Open-channel flow model approximation for controller design." Appl. Math. Modell., 19(9), 525-530.

Sepúlveda, C. (2008). "Instrumentation, model identification and control of an experimental irrigation canal." Ph.D. thesis, Technical Univ. of Catalonia, Barcelona, Spain.

van Overloop, P.-J. (2006). "Model predictive control on open water systems." Ph.D. thesis, Delft Univ. of Technology, Delft, The Netherlands.

van Overloop, P.-J., and Bombois, X. (2012). "Identification of properties of open water channels for controller design." 16th IFAC Symp. on System Identification, Vol. 16, International Federation of Automatic Control, 1019-1024.

van Overloop, P.-J., Clemmens, A., Strand, R., Wagemaker, R., and Bautista, E. (2010a). "Real-time implementation of model predictive control on Maricopa-Stanfield irrigation and drainage district's WM canal." J. Irrig. Drain. Eng., 10.1061/(ASCE)IR.1943-4774 $.0000256,747-756$.

van Overloop, P.-J., Horváth, K., and Aydin, B. E. (2014). "Model predictive control based on an integrator resonance model applied to an open water channel." Control Eng. Pract., 27(0), 54-60.

van Overloop, P.-J., Miltenburg, I. J., Bombois, X., Clemmens, A. J., Strand, R., and van de Giesen, N. (2010b). "Identification of resonance waves in open water channels." Control Eng. Pract., 18(8), 863-872.

Welz, I. G., Litrico, X., Fromion, V., Rijo, M., and Malaterre, P. (2005). "Stability and performance analysis of classical decentralized control of irrigation canals." Proc., 16th IFAC World Congress, Vol. 16, International Federation of Automatic Control.

Weyer, E. (2001). "System identification of an open water channel." Control Eng. Pract., 9(12), 1289-1299. 